\title{
ESR rate can be a marker for coronary artery disease
}

This article was published in the following Dove Press journal:

Vascular Health and Risk Management

17 December 2012

Number of times this article has been viewed

\section{Tasnim Eghbal Eftekhaari}

Clinical Research Development

Center of Shahid Mohammadi Hospital, Research Center

for Cardiovascular Diseases, Department of Research and Technology, Hormozgan University of Medical Sciences, Bandar-eAbbas, Iran
Correspondence: Tasnim Eghbal Eftekhaari

Clinical Research Development Center of Shahid Mohammadi Hospital, Hormozgan University of Medical

Sciences, Bandar-e-Abbas, Iran

Tel +9 876 I333 7| 92

Fax +9 87613337192

Email st.eghbal@yahoo.ca

\section{Letter to the editor}

The aim of Yayan's ${ }^{1}$ study was to utilize the erythrocyte sedimentation rate (ESR) as a rapid guide to identify patients with acute coronary syndrome (ACS) or myocardial infarction. ESR is arguably a nonspecific biomarker which is elevated in almost every condition. Prakash et $\mathrm{al}^{2}$ have pointed to conflicting reports in the literature documenting the tendency of patients with periodontitis to develop anemia. Hence, this study was undertaken to assess whether periodontitis can cause an anemic state by evaluating and comparing the red blood cell count and levels of hemoglobin, hematocrit, ESR, serum iron, and serum ferritin between subjects with and without periodontitis, anemia, rheumatoid arthritis, and other hematologic conditions. ${ }^{1}$ However, this study shows that there is no statistically significant difference between rates of ESR in men and women. The purpose of referring to this reference is that most elderly people suffer from periodontitis and this condition is not negligible given that many older people also suffer for concomitant ischemic heart disease. Inflammation arising within the gastrointestinal tract may be of great importance in the pathogenesis of irritable bowel syndrome, ${ }^{2}$ regarding this fact that ESR is commonly used to assess the acute phase response, ${ }^{3}$ this acute phase response may be nonspecific. Elevated ESR is seen more often in elderly patients than in their younger counterparts $^{3}$ (imagine an elderly patient with elevated ESR and consider whether ESR would be used as the sole basis for diagnosis of heart pain? Of course not!). ESR elevated concomitantly with C-reactive protein is used to confirm adult-onset Still's disease. ${ }^{4}$ In an adult who is a heavy smoker with dyslipidemia, a personal history of Still's disease, and a family history of ischemic heart disease, would you consider Still's disease or ACS first?

Let us suppose a febrile, middle-aged woman is referred with angina pectoris. She has a positive history of anemia, and is suffering from rheumatoid arthritis. Rheumatoid arthritis is generally associated with mild anemia, which is usually normocytic normochromic. Erythropoietin levels are above normal in this patient to compensate for her anemia, hence the normal relationship between EPO in this patient is not associated with the degree of anemia. ${ }^{6}$ Now how can the clinical presentation be judged solely upon basis of ESR, when the fact that CRP and troponin levels may be helpful in management decision of such patients, as the ESR is falsely elevated in response to increased EPO production? ${ }^{6} \mathrm{C}$-reactive protein and troponin levels may be helpful in deciding on the management of such patients, because the ESR is falsely elevated in response to increased erythropoietin production. ${ }^{5}$ 
Another case is the diabetic patient with an infected diabetic foot, mild dyspepsia, and heart burn. In a study reported by Lavery et al, ${ }^{7}$ diabetics were shown to have a significantly higher mean white cell count and ESR than nondiabetic patients $(62.3 \%$ versus $13.7 \%$, respectively, $P<0.0001)$. Lavery et al concluded that "while a glaringly elevated WBC count or ESR should alert the clinician to the possibility of infection, normal values should not be relied upon to rule out a serious event."?

The question arises as to how these patients should be evaluated, given that all of them have electrocardiographic evidence of ischemic heart disease, and the clinical presentation of coronary artery disease (CAD) or ACS varies between diabetics and nondiabetics. Leukocytosis should not be disregarded in the febrile patient with a diabetic foot and according to the article this condition may worsen CAD. ${ }^{7}$ It is proposed that leukocytosis is an independent and prognostic indicator of cardiovascular disease. But how does the doctor know that the elevated ESR is due to ACS and not related to other conditions (ie independent factors and prognostic indicator of CAD, ACS, and outcome), and how can one be certain that the elevated ESR is related to ACS or CAD, or if it is related to infection or other conditions associated with elevated ESR? Because most patients with CAD are in the older age groups, their basal metabolic rate is decreased, so signs of infections may not present as fever or high temperature. It has been reported that granulocytosis may be associated with development of $\mathrm{CAD},{ }^{8}$ but the question arises as to how long should granulocytes be elevated to be a criterion for $\mathrm{CAD}$. If the case is complicated by dehydration, hypoglycemia, or any kind of stress, can the involvement of CAD or ACS be judged relevant in this condition?

Lastly, let us consider the case of a young man suffering from midsternal pain who is a one-pack-year smoker with a history of dyslipidemia. Gastrointestinal involvement is ruled out by endoscopic studies, and ACS is suspected. It is concluded from the paper by Bacci et $\mathrm{al}^{9}$ that ESR, in addition to being a marker of ACS, is also an indicator of dyslipidemia and obesity. Now, how can this marker be used alone to differentiate between ACS and dyslipidemia? In this author's opinion, ESR in conjunction with C-reactive protein and troponin could be useful in predicting the outcome of ACS.

Finally, Yayan et al showed that ESR was prolonged in patients with CAD who had undergone a percutaneous coronary intervention procedure, and suggest that ESR may be a useful additional diagnostic criterion for CAD. ${ }^{1}$ Arguably, a study should be conducted to check inflammatory biomarkers in the absence of confounding factors which may be misleading about the patient, ie, fever, an altered immune system leading to hypothermia, and underlying medical conditions, such as inflammatory bowel disease, rheumatoid arthritis, or even systemic lupus erythematosus. Clearly, the possibility of malignancy should also be kept in mind, because most patients with $\mathrm{CAD}$ are elderly and this type of disease is common in older people.

\section{Disclosure}

The author has no conflict of interest to report.

\section{References}

1. Yayan J. Erythrocyte sedimentation rate as a marker for coronary heart disease. Vasc Health Risk Manag. 2012;8:219-223.

2. Prakash S, Dhingra K, Priya S. Similar hematological and biochemical parameters among periodontitis and control group subjects. Eur J Dent. 2012;6:287-294.

3. Hauser G, Tkalcic M, Pletikosic S, Grabar N, Stimac D. Erythrocyte sedimentation rate - possible role in determining the existence of the low grade inflammation in irritable bowel syndrome patients. Med Hypotheses. 2012;78:818-820.

4. Cuello Garcia CA, Tamez Gomez L, Valdez Ceballos J. Total white blood cell count, erythrosedimentation rate and $\mathrm{C}$-reactive protein for the detection of serious bacterial infections in 0- to 90-day-old infants with fever without a source. An Pediatr (Barc). 2008;68:103-109. Spanish.

5. Iliou C, Papagoras C, Tsifetaki N, Voulgari PV, Drosos AA. Adult-onset Still's disease: clinical, serological and therapeutic considerations. Clin Exp Rheumatol. September 25, 2012. [Epub ahead of print.]

6. Noé G, Augustin J, Hausdorf S, Rich IN, Kubanek B. Serum erythropoietin and transferrin receptors levels in patients with rheumatoid arthritis. Clin Exp Rheumatol. 1995;13:445-451.

7. Lavery LA, Armstrong DG, Quebedeaux TL, Walker SC. Puncture wounds: normal laboratory values in the face of severe infection in diabetics-nondiabetics. Am J Med. 1996;101:521-525.

8. Jia EZ, Yang ZJ, Yuan B, et al. Relationship between leukocyte count and angiographical characteristics of coronary atherosclerosis. Acta Pharmacol Sin. 2005;26:1057-1062.

9. Bacci V, Basso MS, Greco F, et al. Modifications of metabolic and cardiovascular risk factors after weight loss induced by laparoscopic gastric banding. Obes Surg. 2002;12:77-82.
Vascular Health and Risk Management

\section{Publish your work in this journal}

Vascular Health and Risk Management is an international, peerreviewed journal of therapeutics and risk management, focusing on concise rapid reporting of clinical studies on the processes involved in the maintenance of vascular health; the monitoring, prevention and treatment of vascular disease and its sequelae; and the involvement of

\section{Dovepress}

metabolic disorders, particularly diabetes. This journal is indexed on PubMed Central and MedLine. The manuscript management system is completely online and includes a very quick and fair peer-review system, which is all easy to use. Visit http://www.dovepress.com/ testimonials.php to read real quotes from published authors. 